\title{
A New Supplement to Spiritual Leadership from Spiritual Intelligence Conceptions and Etymologic Research
}

\author{
Michael Hagemann \\ Pegaso International, Malta \\ hagemannmichael@web.de
}

Purpose: This study identifies, compiles and compares different definitions of Spiritual Intelligence to detect common principles, it reviews the historical emergence of the word "spiritual" and proposes a new construct of Spiritual Intelligence.

Methodology/approach: A literature review and a systematic creation of principles have been applied.

Findings: It has been detected that the original meaning of "spiritual" has not been considered in the existing research. From the original meaning of "spiritual" a new construct for Spiritual Intelligence has been derived and is proposed for further research.

Originality/value: The origins of "spiritual" have not been studied before, hence the new construct of Spiritual Intelligence will be the new fundament for further research

Keywords: spiritual; leadership; spirituality; framework; intelligence

\section{Introduction}

Both the topic of Spiritual Intelligence (Skrzypińska, 2021) and Spiritual Leadership (Oh \& Wang, 2020) have been widely studied in recent years and share the challenge of having many different definitions and understandings. It is interesting to note that the two topics have developed in parallel and are almost unrelated. The concept of Spiritual Intelligence (SQ) as an own form of intelligence has been critiqued multiple times, e.g., Eysenck, M.W., ed., (1994); Sternberg, (1983). Nevertheless, there are many approaches and definitions that see "spiritual" as its own form of intelligence (Emmons, 2000).

It is similar to the topic "Spiritual Leadership". Many different definitions and basic understandings have recently been well studied and presented (Oh \& Wang, 2020). The model of "Spiritual Leadership," which was one of the first to be studied and then developed over time, was proposed by Fry (2003) and has been developed more widely over the years (Fry et al., 2010; Fry et al., 2011; Fry, 2013; Fry et al., 2017). For this study, we take his model, which at its core consists of the Vision, Hope/Faith, and Altruistic Love triad, influenced by Inner Life/Mindfulness. This Leadership practice aims at spiritual wellbeing through Calling and Membership. Ultimately, it all flows into organizational commitment, unit productivity and life satisfaction (Fry et al., 2017).

In this study, we aim as a first step to compile the different definitions of "Spiritual Intelligence" (SQ), to assess them against commonalities and subsequently to create an overview of the main principles of SQ. As a second step, we will have a look at the historical background of "spiritual". Then, as the word "spiritual" is rooted in the biblical and Christian tradition, we will investigate if there is a deeper or different connotation of "spiritual" and how this could translate into a (secularistic) model or at least how in principle it could look like. Finally, we will combine the results and apply them to Spiritual Leadership.

\section{Many Definitions of Spiritual Intelligence}

There are numerous different definitions of Spiritual Intelligence. Part of our study is to collect them, compile, compare them and look for common patterns. Therefore, the existing literature 
has been scanned and analyzed. Many definitions of SQ revolve around the concept of wholeness - which assumes that everything in the world is somehow connected. For example, according to Wolman (2001), SQ is about the connection of everything. A similar construct of wholeness and expanding the borders can be found in Nobles description of SQ (Noble, 2001). According to Frances Vaughan, "Spiritual Intelligence is concerned with the inner life of mind and spirit and its relationship to being in the world." (Vaughan, 2002).

Furthermore, Vaughan puts forward that SQ "Implies a capacity for a deep understanding of existential questions and insight into multiple levels of consciousness..., awareness of spirit as the ground of being or as the creative life force of evolution." (Vaughan 2002). Dorothy Sisk describes SQ as well as the connection with the universal mind (Sisk, 2002). Kumar defines Spiritual Intelligence as "the capacity of an individual to possess a socially relevant purpose in life by understanding 'self' and having a high degree of conscience, compassion and commitment to human values." (Kumar, V.V., and Mehta, M, 2011). Neena Sawhney defines Spiritual Intelligence as "the human capacity to ask questions about the ultimate meaning of life and the integrated relationship between us and the world in which we live." (Sawhney \& Bansal, 2015). Ken O'Donnell proposes to integrate Spiritual Intelligence, rational intelligence and emotional intelligence. (O'Donnell, 1997). To measure Spiritual Intelligence, he proposes to look at required energy to receive a certain result, respectful relationships, dignity for ourselves and others, staying relaxed in stress, decision-making process, resilience, positive thinking. David King proposes a four-factor model for Spiritual Intelligence (King \& DeCicco, 2009) consisting of critical existential thinking, personal meaning production, transcendental awareness, conscious state expansion. Many scholars define SQ as the capability to develop meaning, vision and value (Kumar, Ashish, 2020).

Intentionally we concentrate on Spiritual Intelligence concepts as such whilst disregarding studies regarding workplace spirituality, e.g., Abdullah, A. G. K., Alzaidiyeen, N. J., \& Aldarabah, I. T., (2009); Giacalone \& Jurkiewicz, (2003).

Four concepts are perceived to describe more comprehensively Spiritual Intelligence.

According to Robert Emmons (Emmons, R.A. 2000), there are five main components of SQ (the fifth was removed by himself later; Emmons, R.A. 2000a):

- The capacity to transcend the physical and material. (Transcendence)

- The ability to experience heightened states of consciousness. (Mysticism)

- The ability to sanctify everyday experience. (Sanctification)

- The ability to utilize spiritual resources to solve problems. (Religious and spiritual coping)

- The capacity to be virtuous. (Virtuous traits)

Danah Zohar and Ian Marshall, in their book "SQ - The ultimate intelligence" developed a comprehensive concept of SQ, proposing 12 indications for a highly developed SQ (Zohar \& Marshall, 2000):

- Self - Awareness: Knowing what I believe in and value; deepen what deeply motivates me.

- Vision and value Led: Acting from principles and deep beliefs and living accordingly.

- Positive use of Adversity: Learning and growing from mistakes and suffering.

- Holistic: Seeing larger patterns, relationships and connections; having a sense of belonging.

- Compassion: Having the quality of "feeling with" and deep empathy.

- Celebration of Diversity: Regarding other people for their differences, not despite them. 
- Field-Independent: Standing against the crowd and having one's own convictions.

- Ask Fundamental "Why" questions: Needing to understand things and get to the bottom of them.

- Ability to Reframe: Standing back from a situation/problem and seeing the bigger picture.

- Spontaneity: Living in and being responsive to the moment.

- Sense of Vocation: Feeling called upon to serve, to give something back.

- Humility: Having the sense of being a player in a larger drama, of one's true place in the world.

According to Yosi Amram, SQ is defined as the ability to apply and embody spiritual resources and qualities to enhance daily functioning and wellbeing (Amram, 2007):

- Consciousness: Developed refined awareness and self-knowledge;

- Grace: Living in alignment with the sacred manifesting love for and trust in life;

- Meaning: Experiencing significance in daily activities through a sense of purpose and a call for service, including in the face of pain and suffering;

- Transcendence: Going beyond the separate egoic self into an interconnected wholeness;

- Truth: Living in open acceptance, curiosity, and love for all creation (all that is);

- Peaceful surrender to Self (Truth, God, Absolute, true nature); and

- Inner-Directedness: inner-freedom aligned in responsible, wise action.

In the Integrated Spiritual Intelligence Scale (ISIS), Amram and Dreyer use only five main domains of the seven characteristics mentioned above: Consciousness, Grace, Meaning, Transcendence and Truth (Amram, Y., and Dryer, C., 2008).

Cindy Wigglesworth came up with a system of four quadrants with a comparable structure to Daniel Goleman's EQ model (Wigglesworth, 2012):

- Higher Self / Ego self Awareness

- Universal Awareness

- Higher Self / Ego self Mastery

- Spiritual Presence / Social Mastery

According to her, SQ is defined as "the ability to act with wisdom and compassion, while maintaining inner and outer peace, regardless of the circumstances." (Wigglesworth, 2006). She breaks down the SQ competencies into 21 skills, arranged into four quadrants Spiritual Intelligence (SQ) Skills.

As the literature research has shown, there are many different definitions of SQ, some of which complement each other (approximately all statements that have to do with the level of consciousness and orientation towards community), some of which call themselves elements of SQ, but could also be elements of other intelligences, especially Emotional Intelligence, and some of which are very controversial - for example regarding the question of what can be called spiritual and what can be called religious. Nevertheless, although the definitions are often fuzzy, clear patterns can be observed. That's why in this study, though we compile the repeating elements of the previously described different definitions and put them into an order.

\section{Four Main Qualifications of SQ}

A deeper look into the different concepts reveals that almost all authors explicitly or implicitly mention four areas, or under which almost all qualitative attributes can be subsumed that are not already covered by another intelligence area, such as Emotional Intelligence. 
Most scholars define elements that occur to the area of awareness of oneself, describing the experience of self-cognition, self-awareness - in philosophical terms: the discovery that I am aware of my deeper self.

The other area is captured by the description of transcendence, which is the opposite of immanence again in philosophical terms. Transcendence refers to the idea of goodness or at least a higher Consciousness.

The third area regularly mentioned as part of the SQ definition refers to the relationship to somebody else, including compassion and the ability to create fulfilling relationships.

Finally, the awareness of the connection of everything and the ethical impetus to take care of the society and the world as a whole is regarded by many as a core definition of Spiritual Intelligence.

To summarize: This fourfold structure of

- Awareness of oneself

- Striving for Transcendence

- Relationship orientation

- World orientation

captures well the main aspects of spirituality that many scholars describe in many different ways.

\section{The Original Meaning of "Spiritual" in the Biblical/Christian Tradition}

Interestingly, the word "spiritual" is used in research on Spiritual Intelligence as well as on Spiritual Leadership without referring to its original meaning. Therefore, the original meaning will be examined first to derive a basic understanding in the secular context.

Spiritual is derived from the Latin word "spiritualis" (Online Etymology Dictionary), which is the translation of the Greek pneuma and Hebrew ruach and means breath or wind. The Latin "spirare" translates to breathing or blowing.

In Christian theology, the "Holy Spirit" is regarded as the third person of the Triune God (Emery, 2012). The term spirituality means living with the Holy Spirit in following Jesus Christ (Emery, 2012). The so-called discipleship refers to a personal transformation, in Christian terms called conversion, and, by following Jesus Christ, a world transformation, in Christian terms called the building of the kingdom of God, respectively the kingdom of love. (Agnew, 2008; Cunningham \& Egan, 1996; Dreyer \& Burrows, 2005).

To summarize: spiritual in the original sense of meaning is directly linked to the Christian religion and means living with the Holy Spirit. In the bible and especially in the New Testament, there can be found a lot of characteristics of what "spiritual" in terms of living with the Holy Spirit means. It can be summarized in the discipleship of Christ, which encompasses the individual transformation and the transformation of the world. The word spirit entails both aspects:

- breathing as a fundamental aspect of human life to survive and to make the "human system" running and transforming

- blowing as a fundamental aspect of deploying energy and effect for transformation

In this study, we ignore the development and further history of Christian spirituality. The word spiritual got even in Christian history different meanings over time. Interestingly enough, in other religious traditions, the term "spiritual" as such doesn't exist originally. We don't discuss either the root causes for the current, mostly common understandings of spiritually that are 
based on the detachment of spirituality from religion since the middle of the $20^{\text {th }}$ century only, c.f. (Kenneson, 2015; Mercadante, 2014).

In this study, we want to build on the original understanding of "spiritual" that translates into the main movements of personal and world transformation. In other words, there is a vertical and a horizontal movement of spiritual.

In light of the original understanding of "spiritual", the personal vertical transformation contains two aspects: the change or adjustment of personal behaviour and the direction of the transformation (discipleship regarding Christ). Trying to "translate" this from the original Christian to a secular context, the two aspects of personal transformation would look like:

- Personal transformation

- Individual transformation

- Transcendental orientation

The horizontal World transformation contains two aspects as well: Christian discipleship is oriented to the commandment of love: "Love your neighbour as yourself" (Mt 22) and through this to transform the society and subsequently the whole world. Hence, the "translation" into the secular context would look like:

- World transformation

- Social (directly - human) orientation

- Society (indirectly - world) transformation.

Following this definition, a secular concept of spiritual life, derived from the original meaning of the word "spiritual", contains the four aspects:

- Individual Transformation

- Transcendental Orientation

- Social Orientation

- Society Transformation

\section{Discussion and Conclusion}

The analysis of research on SQ in recent years has shown that although there are many different definitions of Spiritual Intelligence, almost all research can be summarized in these four areas:

Awareness of oneself, Searching and striving for transcendence, relationship orientation and world orientation. These four dimensions consist of many different attributes. However, the four dimensions cover nearly all of the different definitions and entail elements that are distinguished enough and cannot be put immediately under other concepts like Emotional Intelligence.

The research regarding the original meaning of "spiritual" leads to an interesting discovery. From the word's origin, four different meanings can be derived that correlate highly with the four dimensions chosen to encompass and describe best the dimensions of Spiritual Intelligence.

Table 1: SQ and historical understanding Commonalities in SQ-definitions

Awareness of oneself,

Striving for transcendence,

Relationship orientation and

World orientation

Historical understanding Individual Transformation

Transcendental Orientation

Social Orientation

Society Transformation 
As can be seen at first glance, the biblical-historical investigation of the original meaning of "spiritual" confirms the meanings derived from most descriptions of "Spiritual Intelligence". This results in a new framework of "Spiritual Intelligence" that has not been proposed in this way before. This new framework can become the basis for further research.

At the same time, the framework offers aid to understanding Spiritual Leadership and its implementation. A spiritual leader is someone who 1) is self-aware, rooted in hope/faith, 2) makes a transcendent movement, acts in a visionary way, 3) has a strong relational orientation in altruistic love and 4) does not only act profit-oriented but in the end, contributes to a better world (triple-bottom-line).

Table 2: Comparison SQ/Historical/Spiritual Leadership

\begin{tabular}{|l|l|l|}
\hline Commonalities in SQ-definitions & Historical understanding & Spiritual Leadership \\
\hline Awareness & Individual Transformation & Hope/Faith \\
\hline Transcendence & Transcendental Orientation & Vision/Calling \\
\hline Relationship & Social Orientation & Altruistic Love \\
\hline World orientation & Society Transformation & Triple bottom-line \\
\hline
\end{tabular}

\section{Limitations and Further Research}

We tried to achieve in this study a review of definitions of Spiritual Intelligence, a summary, compilation and assessment of the principles to put them into a simple structure. From there, we derived the main principles and researched the original meaning of the word spiritual and put a concept forward of how Spiritual Leadership can be formed.

The first limitation of this study is the focus on the biblical meaning of "spiritual" and the neglect of historical development. Further research should look especially at the different meanings of "spiritual" in the different centuries, taking into account the philosophical and theological background of the spirituality of the last 2000 years and research the development of the past 50 years in-depth.

In addition, the traditions of spirituality in other religions were out of scope for this study and should be further researched. This includes an investigation into the extent to which Eastern ideas indirectly influence spirituality. At this point, the difference between mystical religions and so-called revelation religions should also be considered.

The overall topic of Spiritual Leadership is an important interdisciplinary research theme. Therefore, scholars from theology, psychology, neurobiology, social science, and business administration should commonly enhance the understanding and usage of the proposed model to clarify the "Spiritual Leadership further" framework.

\section{References}

Abdullah, A. G. K., Alzaidiyeen, N. J., \& Aldarabah, I. T. (2009). Workplace spirituality and leadership effectiveness among educational managers in Malaysia. European Journal of Social Sciences, 10(2), 304316.

Agnew, U. (2008). With wisdom seeking God: the academic study of spirituality;[first European Spirituality Conference held at Milltown Institute, Dublin, Ireland in June 2004].

Amram, Y. (2007). The seven dimensions of Spiritual Intelligence: An Ecumenical, Grounded Theory Paper accepted to the 115th ANNUAL Conference of the APA, San Francisco.

Amram, Y., and Dryer, C. (2008). "The integrated Spiritual Intelligence scale (ISIS): Development and preliminary validation." 116th annual conference of the American Psychological Association, Boston, MA.

Cunningham, L., \& Egan, K. J. (1996). Christian spirituality: Themes from the tradition. Paulist Press.

Dreyer, E., \& Burrows, M. S. (2005). Minding the Spirit: The study of Christian spirituality. The Johns Hopkins University Press.

Emery, G. (2012). The Trinity: An introduction to Catholic doctrine on the Triune God. Thomistic ressourcement series: volume 1. Catholic University of America Press. https://doi.org/10.2307/j.ctt3fgqdw 
Emmons, R. A. (2000). Is Spirituality an Intelligence? Motivation, Cognition, and the Psychology of Ultimate Concern. International Journal for the Psychology of Religion, 10(1), 3-26. https://doi.org/10.1207/S15327582IJPR1001_2

Eysenck, M.W., ed. (1994). The Blackwell dictionary of cognitive psychology, Blackwell Publishers, pp. 192-193.

Fry, L. W. (2003). Toward a theory of Spiritual Leadership. The Leadership Quarterly, 14(6), 693-727. https://doi.org/10.1016/j.leaqua.2003.09.001

Fry, L. W. (Ed.). (2013). Maximizing the Triple Bottom Line Through Spiritual Leadership. Stanford University Press.

Fry, L. W., Hannah, S. T., Noel, M., \& Walumbwa, F. O. (2011). Retracted: Impact of Spiritual Leadership on unit performance. The Leadership Quarterly, 22(2), 259-270. https://doi.org/10.1016/j.leaqua.2011.02.002

Fry, L. W., Latham, J. R., Clinebell, S. K., \& Krahnke, K. (2017). Spiritual leadership as a model for performance excellence: A study of Baldrige award recipients. Journal of Management, Spirituality \& Religion, 14(1), 22-47. https://doi.org/10.1080/14766086.2016.1202130

Fry, L. W., Matherly, L. L., \& Ouimet, J.-R. (2010). The Spiritual Leadership Balanced Scorecard Business Model: The case of the Cordon Bleu-Tomasso Corporation. Journal of Management, Spirituality \& Religion, 7(4), 283-314. https://doi.org/10.1080/14766086.2010.524983

Giacalone, R. A., \& Jurkiewicz, C. L. (2003). Handbook of workplace spirituality and organizational performance. Sharpe.

Kenneson, P. D. (2015). What's in a Name? A Brief Introduction to the "Spiritual But Not Religious". Liturgy, 30(3), 3-13. https://doi.org/10.1080/0458063X.2015.1019259

King, D. B., \& DeCicco, T. L. (2009). A Viable Model and Self-Report Measure of Spiritual Intelligence. International Journal of Transpersonal Studies, 28(1), 68-85. https://doi.org/10.24972/ijts.2009.28.1.68

Kumar, V.V., and Mehta, M. (2011). Gaining adaptive orientation through spiritual and emotional intelligence. In A.K. Chauhan \& S.S. Nathawat (Eds.), New Facets of Positivism (pp 281-301). Delhi: Macmillan Publishers India.

Mercadante, L. A. (2014). Belief without borders: Inside the minds of the spiritual but not religious. Oxford University Press.

Noble, K. D. (2001). Riding the windhorse: Spiritual Intelligence and the growth of the self. Hampton Press.

O'Donnell, K. (1997). Endoquality - as dimensões emotionais e espirituais do ser humano nas organanizões. Casa da Qualidade. pp. 44-46.

Oh, J., \& Wang, J. (2020). Spiritual leadership: Current status and Agenda for future research and practice. Journal of Management, Spirituality \& Religion, 17(3), 223-248. https://doi.org/10.1080/14766086.2020.1728568

Online Etymology Dictionary. spiritual (adj.). https://www.etymonline.com/search?q=spiritual;

Sawhney, N., \& Bansal, S. (2015). Comparative Study of Spiritual Intelligence among Workforce of Education and Corporate Sector. Indian Journal of Psychological Science 6.1, 93-100.

Sisk, D. (2002). Spiritual Intelligence: The Tenth Intelligence that Integrates all other Intelligences. Gifted Education International, 16(3), 208-213. https://doi.org/10.1177/026142940201600304

Skrzypińska, K. (2021). Does Spiritual Intelligence (SI) Exist? A Theoretical Investigation of a Tool Useful for Finding the Meaning of Life. Journal of Religion and Health, 60(1), 500-516. https://doi.org/10.1007/s10943-020-01005-8

Sternberg, R. J. (1983). How much Gall is too much gall? Review of Frames of Mind: The theory of multiple intelligences. Contemporary Education Review. 2 (3): 215-224.

Vaughan, F. (2002). What is Spiritual Intelligence? Journal of Humanistic Psychology, 42(2), 16-33. https://doi.org/10.1177/0022167802422003

Wigglesworth, C. (2006). Why Spiritual Intelligence is essential to mature leadership. Integral Leadership Review Volume VI, No. 3.

Wigglesworth, C. (2012). SQ21: The 21 Skills of Spiritual Intelligence, New York: Select Books.

Wolman, R. (2001). Thinking with your soul: Spiritual Intelligence and why it matters. New York: Harmony.

Zohar, D., \& Marshall, I. (2000). SQ: Spirituelle Intelligenz ; Die notwendige Frage nach dem Sinn - Wie das menschliche Gehirn Kreativität entstehen lässt, Visionen und Werte entwickelt und dem einzelnen Leben Sinn verleiht. Scherz. 